\title{
Dendritic cells transduced with glioma- expressed antigen 2 recombinant adenovirus induces specific cytotoxic lymphocyte response and anti-tumor effect in mice
}

\author{
Gaohai Shao', Changlong Zhou², Kunlong Ma', Wang Zhao², Guibo Feng ${ }^{2}$, Qijiang Xiong ${ }^{2}$, Ling Yang ${ }^{2}$ and \\ Zhao Yang ${ }^{2^{*}}$
}

\begin{abstract}
Introduction: Glioma is an aggressive common cancer with high mortality worldwide. Up to date, the effective medical therapeutical strategy is limited. Numerous previous studies have indicated that glioma-expressed antigen 2 (GLEA2) might be an attractive prognostic glioma biomarker.

Methods: In this experiment, dendritic cells (DCs) transduced with GLEA2 recombinant adenovirus were utilized to generate cytotoxic lymphocytes (CTLs) in vitro. Additionally, trimera mice were immunized with the transduced DCs to generate CTLS in vivo.

Results: The data demonstrated that GLEA2 transduced DCs could effectively generate specific CTL response against glioma without lysing autologous lymphocytes. Moreover, GLEA2 transduced DCs significantly attenuated the tumor growth and prolonged the life span of tumor bearing mice.

Conclusions: These findings suggested that DCs transduced with GLEA2 recombinant adenovirus could generate effective CTL mediated anti-tumor response, and might represent insight in glioma therapy.
\end{abstract}

Keywords: Dendritic cells, GLEA2, CTL, Anti-tumor

\section{Introduction}

Gliomas are the most common primary central nervous system tumors [1-3]. Glioblastomas represent $50 \%$ of all gliomas in adults with an extremely poor prognosis [4-6]. Despite innovative therapeutic methods such as surgical resection, chemotherapy, and radiation therapy, the survival ratio is very low [7-9]. Therefore, the novel therapeutic approaches are in great need.

GLEA2 was identified as a novel antigen termed glioma-expressed antigen 2 (GLEA2) inducing immune response in glioma patients [10]. The evidence found an immune response against GLEA2 in 17 patients (43\%).

\footnotetext{
* Correspondence: yangzhao5140@sohu.com

${ }^{2}$ Department of Neurology, Yongchuan Hospital, Chongqing Medical

University, Chongqing 402160, China

Full list of author information is available at the end of the article
}

In addition, screening with allogenic sera from other glioma patients revealed GLEA2 directed antibodies in two out of five pilocytic astrocytomas and in one out of two astrocytomas [11]. In serological analyses by the SEREX (Serological analysis of expression cDNA libraries) technology, GLEA2 were found to frequently elicit immune responses in sera of GBM patients and acted as a prognostic biomarker for glioma [12]. Therefore, GLEA2 may be act as a new target in cancer therapy.

Specific CTLs mediated cellular immunotherapy has been utilized to treat malignant tumors [13-15]. Antigen presentation is an important step to elicit adaptive immune response. Dendritic cells are the potent professional antigen-presenting cells and have the robust antigenpresenting efficiency [16-18]. They can present a tumor associated antigen to the immune system and generate 
specific immune response. Dendritic cells transduced with various tumor associated antigens (TAAs) can initiate specific antitumor effects in vitro and in vivo [19-21].

However, the related evidence linking GLEA2 to glioma therapy has not been reported. In this experiment, dendritic cells transduced with GLEA2 were constructed and the capability of inducing immuno- responses was detected. We found that GLEA2 transduced DCs could elicit specific CTL response against glioma without lysing autologous lymphocytes. In addition, GLEA2 transduced DCs could also inhibit the tumor growth and improve the life span of tumor bearing mice.

\section{Materials and methods}

\section{Mice, cells, and other reagents}

NOD/SCID and BALB/c mice were purchased from the Laboratory Animal Institute of Beijing Medical University and were used at 6 weeks of age. Animals were bred in the Laboratory Animal Center and all studies were performed in agreement with the local ethics committee. The glioma cell line U251, was purchased from American Type Culture Collection. The cell line was maintained as monolayers in Dulbecco's modified Eagle' medium containing $10 \%$ heat- inactivated fetal bovine serum kept at $37^{\circ} \mathrm{C}$ in a humidified atmosphere of $5 \% \mathrm{CO}_{2}$ in air.

\section{Construction of recombinant adenovirus encoding GLEA2} The recombinant adenovirus vector encoding murine GLEA2 was constructed using the Adeno-XTM Expression System (Clontech, Palo Alto, CA, USA) according to the manufacturer's instructions. Briefly, the GLEA2 cDNA was cloned into the shuttle vector pDC315 and sequenced. The desired replication-deficient adenovirus containing the full length cDNA of GLEA2 was generated by homologous recombination through co-transfection of plasmids pDC315GLEA2 and pBHG1oXE1, 3Cre in HEK 293 cells using the DOTAP liposome reagent (Roch, Germany). After several rounds of plaque purification, the adenovirus containing the GLEA2 gene was amplified and purified from cell lysates by banding twice in $\mathrm{CsCl}$ density gradients. Viral products were desalted and stored at $-80^{\circ} \mathrm{C}$ in phosphate buffered saline (PBS) containing $10 \%$ glycerol $(\mathrm{v} / \mathrm{v})$. The infectious titer was determined by a standard plaque assay. A second recombinant, El-, E3-deleted adenovirus carrying the LacZ protein under the control of CMV promoter (AdLacZ), was used as a control vector.

\section{Preparation of Trimera mice}

Male nonobese diabetes/severe combined immunodeficiency (NOD/SCID) and BALB/c (H-2d) mice, 6-10 weeks old at the onset of experiments, were purchased from the Institute of Animal of Beijing Medical University (Beijing, China). During the course of experiments, the mice were kept in pathogen free animal facilities with controlled temperature and humidity, under a 12-h light/dark cycle, and with food and water containing cyprofloxacin $(20 \mathrm{lg} / \mathrm{ml})$. All animals were acclimated for at least 1 week before the experiments. Animal care and use were performed in accordance with the guidelines of the Dutch Committee of Animal Experiments. Recipient $\mathrm{BALB} / \mathrm{c}$ mice received a lethal dose of total body irradiation (i.e., day 0, $3.5 \mathrm{~Gy}$ and day 3, 9.5 Gy). On days $4-6,3 \times 10^{6}$ mixed bone marrow cells (in $0.2 \mathrm{ml}$ PBS) from NOD/SCID mice were transferred into each irradiated recipient by i.v. injection. One day after bone marrow infusion, each recipient mouse was.

injected (i.p.) with $2 \times 10^{8}$ human PBMCs (HLA-A2). All mice were kept under specific pathogen-free conditions, fed with sterile food and acid water containing cyprofloxacin $(20 \mu \mathrm{g} / \mathrm{ml})$.

\section{Generation of DCs}

PBMCs were obtained by Ficoll-Hypaque (Celbio S.P.A., Italy) gradient separation of buffy coats of heparinized blood samples collected from HLA-A(*)02.01-typed healthy human donors who provided written informed consent. The DCs used for in vitro CTL stimulation were generated from autologous PBMCs $\left(10^{7}\right.$ cell $\left./ \mathrm{mL}\right)$ seeded in complete RPMI-1640 medium with the addition of $5 \%$ heat-inactivated human $\mathrm{AB}$ serum, 2 $\mathrm{mM} \mathrm{L}$-glutamine and $100 \mathrm{U} / \mathrm{mL}$ penicillin/streptomycin at $37^{\circ} \mathrm{C}$ in $5 \% \mathrm{CO}_{2}$ humidified atmosphere for $4 \mathrm{~h}$. Nonadherent cells were removed, whereas adherent cells where cultured for 7 days in medium containing $50 \mathrm{ng} /$ $\mathrm{mL}$ of granulocyte-macrophage colony stimulating factor (GM-CSF) and $0.05 \mathrm{ng} / \mathrm{mL}$ of interleukin-4 (IL-4) (both purchased from R\&D System, Minneapolis, MN); in all cases, the medium containing GM-CSF and IL-4 was replaced every $48 \mathrm{~h}$. FACS analysis demonstrated that DCs expressed high level of CD11c and MHC Class II (as shown in Additional file 1: Figure S1).

\section{Adenovirus-mediated gene transfer}

Transduction of DCs with Ad-GLEA2 was done in 6well plates with $1 \times 10^{6}$ DCs cells/well in $3 \mathrm{~mL}$ RPMI1640 medium containing 10\% FBS. Virus was added to the wells at an MOI of 200 and the DCs were harvested after $24 \mathrm{~h}$ of incubation.

\section{Western blot analysis}

Total cellular proteins were extracted from cultured cells using RIPA lysis buffer (50 mM Tris pH 7.5, $150 \mathrm{mM} \mathrm{NaCl}$, $1 \%$ Nonidet P-40, $0.1 \%$ SDS, $1 \%$ sodium deoxycholate) supplemented with Protease Inhibitor Cocktail (Roche). Lysates were cleared by centrifugation at $16,000 \mathrm{~g}$ at $4{ }^{\circ} \mathrm{C}$ for 20 mins and supernatants containing proteins were collected. For immunoblotting, $30 \mu \mathrm{g}$ of extracted proteins diluted in SDS-sampling buffer was resolved by SDS-PAGE 
(10-15\%) gels and then electroblotted onto nitrocellulose membranes (Hybond ECL, Amersham Life Science). Following transfer, membranes were blocked with $5 \%(\mathrm{w} / \mathrm{v})$ skim milk in TBS-Tween (TBS; $0.05 \mathrm{M}$ Tris, $0.15 \mathrm{M} \mathrm{NaCl}$, $\mathrm{pH} 7.5$ and $0.1 \%$ Tween-20) for $1 \mathrm{~h}$ and then probed with primary antibodies diluted in $1 \%(\mathrm{w} / \mathrm{v})$ skim milk powder in TBS-Tween at $4{ }^{\circ} \mathrm{C}$ overnight. Membranes were washed and then incubated with HRP-conjugated secondary antibodies and antibody reactivity was detected by the Western Lightning Ultra Detection Kit (PerkinElmer, Waltham, MA, USA) using the FujiFilm LAS-3000 Gel Documentation System (FujiFilm, Tokyo, Japan) and its associated software.

\section{Induction of GLEA2 specific CTLs in vitro}

GLEA2-specific cytotoxic T lymphocytes (CTLs) were generated in vitro by weekly stimulation of nonadherent peripheral blood lymphocytes with irradiated autologous DCs, which were transduced with Ad-GLEA2. In brief, DCs were transduced with Ad-GLEA2 at an MOI of 200 and cultured for 2 days in fresh cytokine-supplemented medium containing $1000 \mathrm{U} / \mathrm{ml}$ of TNF- $\gamma$. They were then irradiated with 40 Gy which entirely prevented outgrowth in the control cultures. The cells were then seeded into 24-well plates at $5 \times 10^{4}$ cells per well. The splenocytes were added at $1 \times$ $10^{6}$ per well. After 7 days of co-culture with stimulators, the lymphocytes were harvested and resuspended at $5 \times 10^{5}$ per well. The cells were then re-stimulated with $1 \times 10^{5}$ cells per well of irradiated GLEA2 transduced DC. After 3 days, the cells were fed with $50 \mathrm{U} / \mathrm{ml}$ of IL-2. The cells were harvested 4 days later and then re-stimulated. On the 21st day, after harvesting the cells, their specificities were evaluated by a $4-\mathrm{h}{ }^{51} \mathrm{Cr}$ release assay. Effector cells that were generated from Ad-LacZ transduced DCs or T lymphocytes stimulated by only IL-2 were used as a control.

\section{Chromium release assays}

The presence of specific CTLs was measured in a standard 4-h chromium release assay. Briefly, target cells are labeled with ${ }^{51} \mathrm{Cr}\left(100 \mu \mathrm{Ci}\right.$ per $1 \times 10^{6}$ cells; Amersham Biosciences Corp). After extensive washing, target cells are incubated with $\mathrm{T}$ cells at $\mathrm{E}$ : $\mathrm{T}$ ratios ranging from $100: 1$ to $25: 1$. All conditions were done in triplicate. Plates were incubated for $4-5 \mathrm{~h}$ at $37^{\circ} \mathrm{C}$ in $5 \% \mathrm{CO}_{2}$. Supernatant fluids were harvested and radioactivity was measured in a gamma counter. Percentage specific lysis was determined from the following formula: $100 \times$ (experimental release-spontaneous release)/(maximum release-spontaneous release). Maximum release was determined by lysis of radiolabeled targets in $1 \%$ SDS.

\section{ELISPOT analysis}

A cytokine enzyme-linked immunospot (ELISPOT) assay designed to enumerate interferon (IFN)- $\alpha$-secreting cells in preparations of PBMCs was used to measure the frequency of activated $\mathrm{T}$ cells with the ability to detect cytokine release in response to specific antigen peptides. According to the procedure, $1 \times 10^{6}$ splenocytes were incubated and stimulated in the wells of ELISPOT plates precoated with a high-affinity $m A b$ to IFN- $\alpha$. Subsequently, cells were washed away. The areas in which the cytokines had been bound were detected by a combination of biotinylated anti-cytokine detection $\mathrm{mAbs}$ and $\phi$ labeled goat anti-biotin $\mathrm{mAb}$. A final reagent was added to the assay in order to promote precipitation of silver on $\phi$ revealing the site of cytokine secretion (i.e., spot formation). Fresh medium containing phytohemagglutinin (PHA, $10 \mu \mathrm{g} / \mathrm{mL}$ ) were used as positive controls, whereas unloaded DCs in fresh medium was used as a negative control. The spots were finally evaluated by using an ELISPOT reader (A.EL.VIS GMBH, Hannover, Germany). Results were expressed as number of spots/field.

\section{Vaccination and tumor challenge experiments}

All animal protocols were approved under guidelines of the animal protection act. Trimera mice were challenged with subcutaneously.

(s.c.) injection of $1 \times 10^{6} \mathrm{U} 251$ cells into the left flank to induce primary tumor model. After 10 days, Trimera mice were immunized s.c. in the base of the tail with $1 \times 10^{6}$ transduced DCs in $100 \mu \mathrm{l}$ PBS for three times once a week. Control mice received the same volume of PBS. The tumor volume and mean lifespan of mice were observed. Tumor volume was measured in two dimensions and calculated as follows: length $/ 2 \times$ width $^{2}$.

\section{Adoptive transfer assay}

Trimera mice were challenged with subcutaneously (s.c.) injection of $1 \times 10^{6} \mathrm{U} 251$ cells into the left flank to induce primary tumor model.

After 10 days, Trimera mice were injected i.v. of $1 \times$ $10^{7}$ lymphocytes.

Control mice received the same volume of PBS. The tumor volume and mean lifespan of mice were observed. Tumor volume was measured in two dimensions and calculated as follows: length $/ 2 \times$ width $^{2}$.

\section{Statistics}

All the experiments were run in triplicate, and the results are given as means \pm SD of triplicate determinations. The statistical significance of differential findings between experimental groups and controls were determined by ANOVA and post-hoc analysis, and considered significant if $P<0.05$. All statistical analyses were carried out with SPSS 11.5 software.

\section{Results}

Gene induction and GLEA2 protein analysis. 
To detect the capability of adenovirus transduction, we analyzed GLEA2 expression of DCs by Western blot assay. DCs were transduced with Ad- GLEA2 or Ad-LacZ at MOI 200 for $24 \mathrm{~h}$ with protocols mentioned above. The data demonstrated that GLEA2 protein was detected after Ad- GLEA2 transduction. However, GLEA2 protein can not been detected in Ad-LacZ and non-treated DCs groups (Fig. 1a). The results suggested that Ad-GLEA2 could transduce into DCs and mediate GLEA2 protein expression. In addition, we also analyzed GLEA2 expression of U251 cells by Western blot assay. The results suggested that GLEA2 was highly expressed in U251 cells. However, Ad-GLEA2 shRNA significantly inhibited GLEA2 in U251 cells (Fig. 1b).

\section{Induction of GLEA2-specific CTL activity in vitro}

To detect the capability of adenovirus transduced DCs, we analyzed GLEA2-specific CTL activity in vitro.

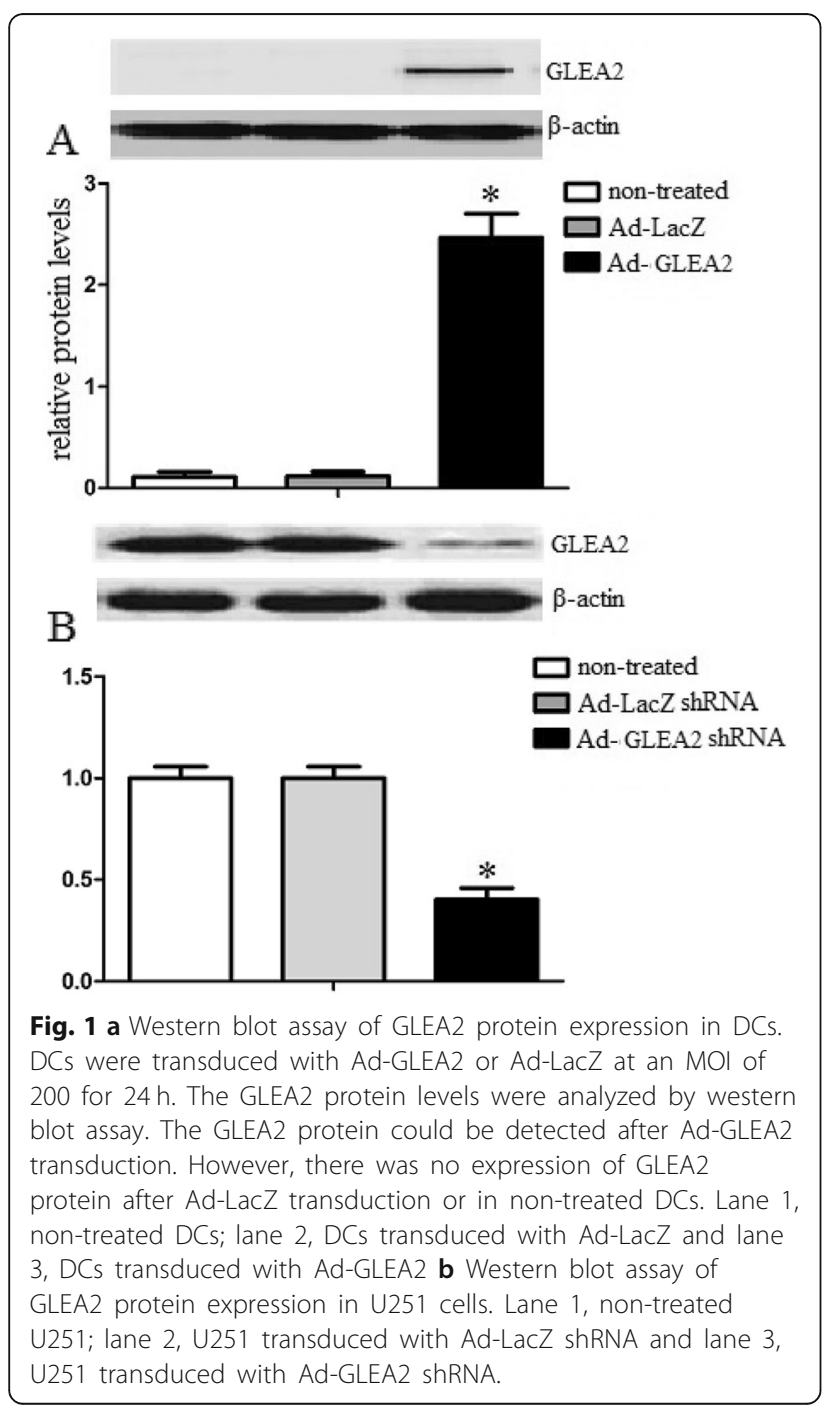

GLEA2-specific cytotoxic T lymphocytes (CTLs) were elicited in vitro by weekly stimulation of peripheral blood lymphocytes with irradiated autologous DCs transduced with Ad-GLEA2. GLEA2-specific CTLs were tested against U251 cells or autologous lymphocytes. CTLs generated from Ad-LacZ transduced DCs and CTLs generated from non-treated DCs were used as controls. The data demonstrated that GLEA2-specific CTLs induced by Ad-GLEA2 caused greater than $40 \%$ lysis of U251 cells at an E:T ratio of 100:1. However, AdLacZ and non-treated DCs induced CTLs could not lyse U251 cells (Fig. 2).

\section{None specific lysis assay}

To explore whether adenovirus transduced DCs could elicit GLEA2 specific CTLs, we utilized CD3/CD28 activated DCs to elicit CTLs. We found that CTLs elicited by CD3/CD28 activated DCs could not lyse U251 cells (Fig. 3a). In addition, to explore whether GLEA2 specific CTLs would lyse nonspecific target cells, U251 cells lacking GLEA2 expression were utilized as a target cells. We found that lysis ratio of GLEA2 specific CTLs to U251 cells lacking GLEA2 expression was significantly attenuated in vitro (Fig. 3b). The data suggested that GLEA2 specific CTLs had no immune system side effects on none specific target cells.

\section{Induction of TNF-a-producing CTLs}

To explore whether adenovirus transduced DCs could induce CTLs to generate cytokines, we analyzed the TNF- $\alpha$ by ELISPOT assay. GLEA2-specific cytotoxic $\mathrm{T}$ lymphocytes (CTLs) were generated in vitro by weekly stimulation of peripheral blood lymphocytes with irradiated autologous DCs transduced with Ad-

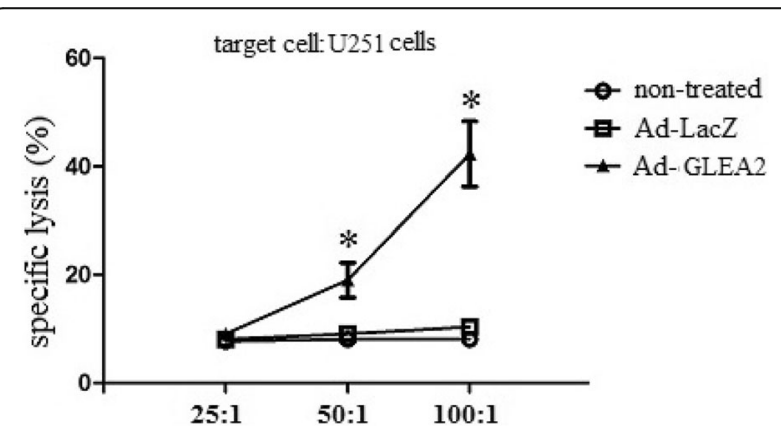

Fig. 2 Specific lysis of target cells in vitro. GLEA2-specific cytotoxic T lymphocytes (CTLs) were elicited in vitro by weekly stimulation of peripheral blood lymphocytes with irradiated autologous DCs transduced with Ad-GLEA2. GLEA2-specific CTLs were tested against U251 cells. CTLs generated from Ad-LacZ transduced DCs and CTLs generated from non-treated DCs were used as controls. Triplicate experiments showed consistent results. Compared with controls, ${ }^{*} P<0.05$. 


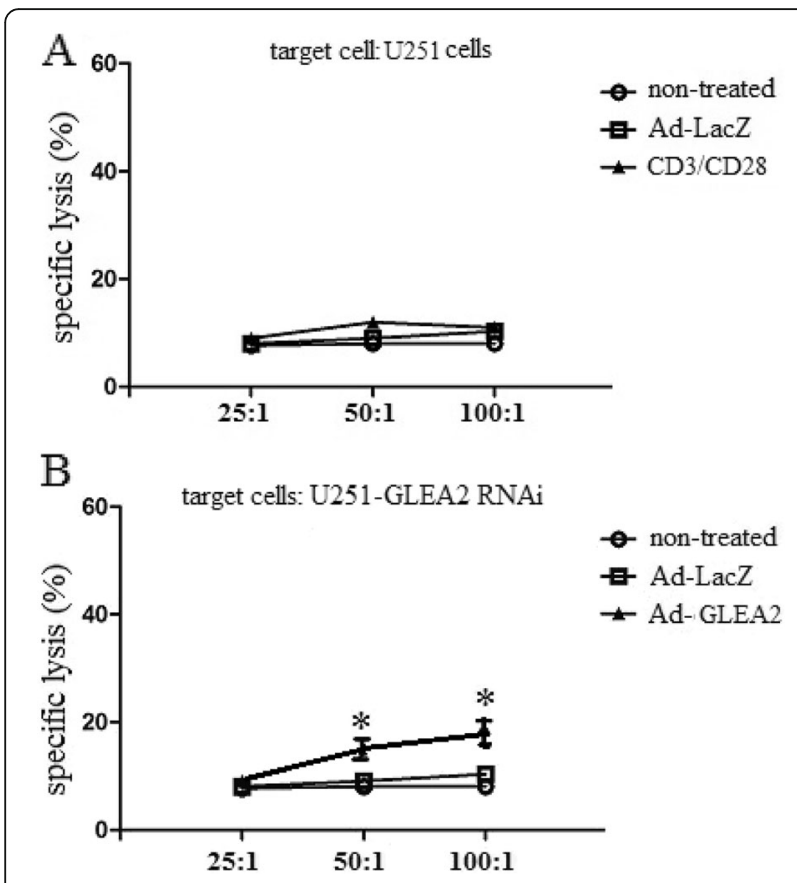

Fig. 3 GLEA2-specific CTLs were tested for their ability to lyse U251 cells expressing GLEA2. a GLEA2-specific cytotoxic T lymphocytes (CTLS) were generated in vitro with $5 \mu \mathrm{g} / \mathrm{ml}$ of anti-CD3 antibody (clone 17A2; Biolegend) pre-bound to the culture plate and $2 \mu \mathrm{g} / \mathrm{ml}$ of soluble anti-CD28 antibody (clone 37.51 ; Biolegend) at $37^{\circ} \mathrm{C}$ for $3 \mathrm{ds}$. GLEA2-specific CTLs were tested against U251 cells. b GLEA2-specific cytotoxic T lymphocytes (CTLS) were generated by weekly stimulation of nonadherent peripheral blood lymphocytes with irradiated, autologous DCs transduced with Ad-GLEA2. GLEA2-specific CTLs were tested against U251 cells lacking GLEA2 expression. CTLs generated from Ad-LacZ transduced DCs and effector cells generated from $T$ lymphocytes stimulated by PBS were used as controls. Experiments performed in triplicate showed consistent results.

GLEA2. The single-cell suspensions of peripheral blood lymphocytes were prepared as effector cells to quantify specific TNF- $\alpha$ releasing cells. The results demonstrated that Ad-GLEA2 transduced DCs could induce high frequencies of TNF- $\alpha$-producing $\mathrm{T}$ cells compared with control groups (Fig. 4). The data suggested that Ad-GLEA2 transduced DCs promoted CTL activity.

\section{Inhibition of tumor growth}

To identify whether the Ad-GLEA2 could exert antitumor capability in vivo, the mice $(n=10)$ were challenged with an s.c. injection of $1 \times 10^{6} \mathrm{U} 251$ cells into the left flank to induce a primary tumor model. 10 days after tumor challenge, Trimera mice were immunized s.c. in the base of the tail with $1 \times 10^{6}$ transduced DCs in $100 \mu \mathrm{l}$ PBS for three times once a week. Tumor volume and lifespan of the mice were observed. We found the tumor volume expanded

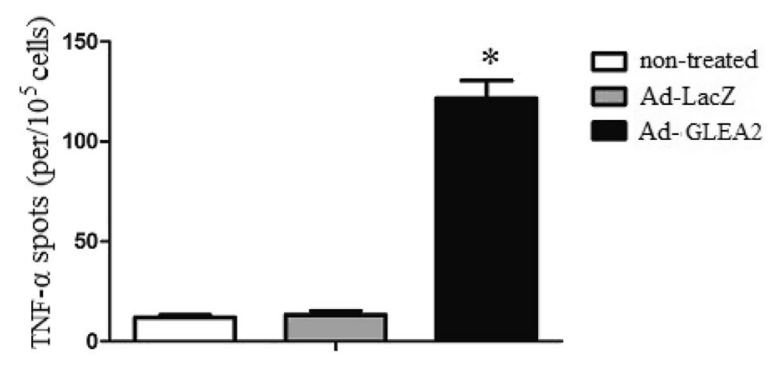

Fig. 4 Specific TNF-a by ELISPOT assayGLEA2-specific cytotoxic T lymphocytes (CTLS) were generated in vitro by weekly stimulation of splenocytes with irradiated autologous DCs transduced with Ad-GLEA2. The single-cell suspensions of splenocytes were prepared as effector cells to quantify specific TNF-a releasing cells. Triplicate experiments showed consistent results. Compared with controls, ${ }^{*} P<0.05$.

rapidly after 25 days of tumor challenge in the PBS and Ad-LacZ groups. However, in the Ad-GLEA2 group, the tumor volume expanded slowly (Fig. 5a). In addition, the mean lifespan of tumor bearing mice in the Ad-GLEA2 group was prolonged significantly (Fig. 5b). In addition, to further analyze whether elicited $\mathrm{T}$ cells has the potential to anti-tumor, we transferred $\mathrm{T}$ cells into tumor bearing mice, and detected the tumor volume and mean lifespan. The data demonstrated that Ad-GLEA2 elicited $\mathrm{T}$ cells had ideal anti-tumor efficiency (Fig. $5 \mathrm{c}$ and d). These data suggested that Ad-GLEA2 trasduced DCs had the antitumor capability in vivo.

\section{Discussion}

Glioma is one of the most common malignancies in the world. Resection, chemo-embolization, surgery ablation and radiotherapy are the most commonly curative treatments in the clinic [22-24]. However, the postoperative 2-year recurrence rate remains high and the long-term survival prognosis of patients is still poor [25-27].

Immunotherapy has been regarded as a promising therapeutic strategy for malignant tumors in the past years, which has the advantages of high anti-tumor efficiency and weak side effects [28-30]. One of the opinions for tumor immunotherapy is tumorassociated antigen (TAA) vaccine that could induce specific and long-lasting immune response [30-32]. GLEA2 is a novel antigen which is expressed in glioma and induces an immune response in more than $43 \%$ of all glioma patients [33]. However, the immunotherapy strategy based on GLEA2 has not been reported.

Firstly, DCs were transduced with Ad-GLEA2, and GLEA2 expression was detected. The results suggested that Ad-GLEA2 could induce into DCs and mediate 

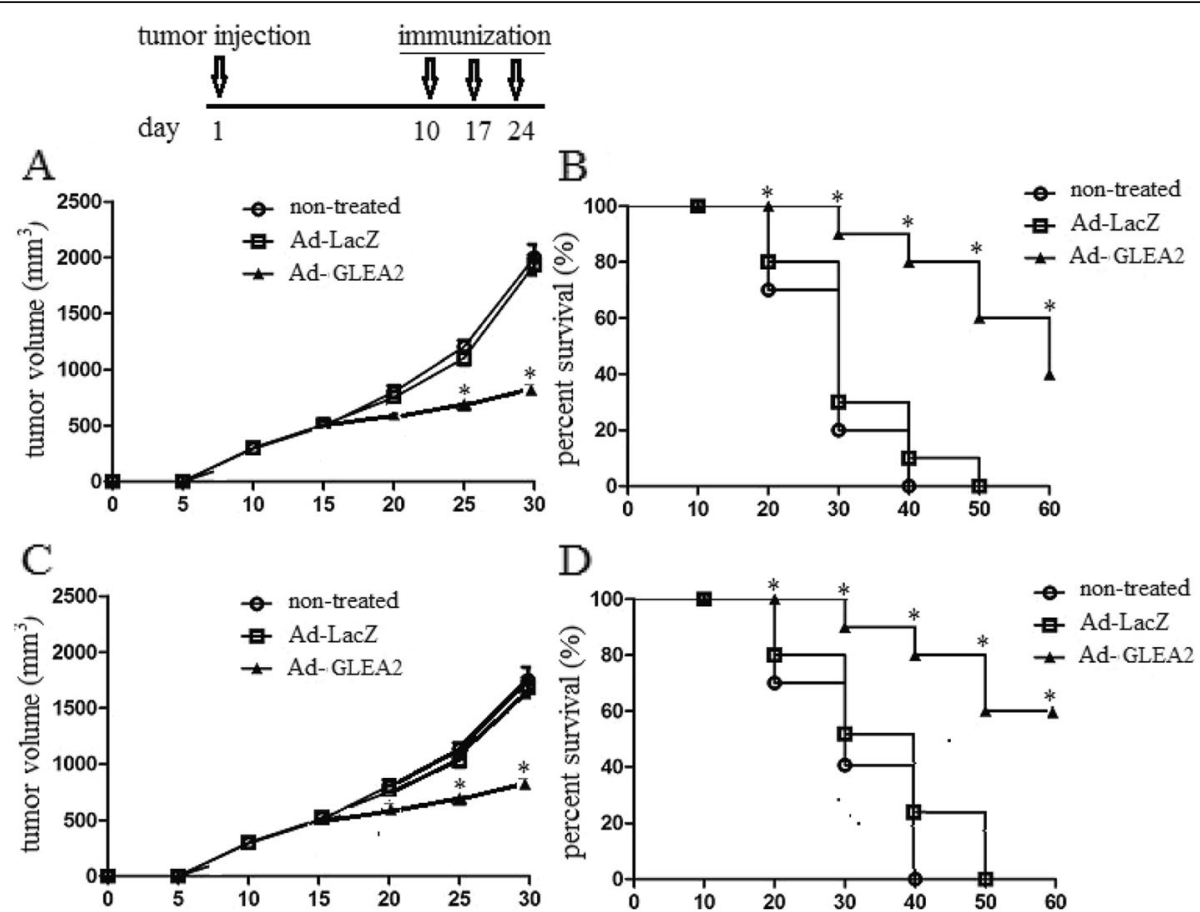

Fig. 5 Primary tumor growth and the average lifespan of mice. The mice $(n=10)$ were challenged with an s.c. injection of $1 \times 10^{6} \mathrm{U} 251$ cells into the left flank to induce a primary tumor model. $\mathbf{a}$ and $\mathbf{b}$. 10 days after tumor challenge, Trimera mice were immunized s.c. in the base of the tail with $1 \times 10^{6}$ transduced DCs in $100 \mu \mathrm{l}$ PBS for three times once a week. The average tumor volume and average lifespan of mice are depicted. c and $\mathbf{d}$. 10 days after tumor challenge, Trimera mice were injected i.v. of $1 \times 10^{7}$ lymphocytes. Control mice received the same volume of PBS. The tumor volume and mean lifespan of mice were observed. Experiments performed in triplicate showed consistent results

GLEA2 protein expression. Secondly, Ad-GLEA2 transduced DCs were utilized to elicit GLEA2-specific CTL activity in vitro. The data suggested that Ad-GLEA2 transduced DCs promoted CTL activity without obvious immune system side effects. Lastly, the tumor bearing mice were immunized with Ad-GLEA2 transduced DCs, and the tumor volume and lifespan of the mice were observed. These data suggested that Ad-GLEA2 transduced DCs had the anti-tumor capability in vivo.

\section{Conclusions}

Taken together, our data suggested that DCs transduced with Ad-GLEA2 could elicit a robust anti-tumor immune response against glioma in vitro and in vivo.

\section{Supplementary information}

Supplementary information accompanies this paper at https://doi.org/10. 1186/s12950-020-0239-6.

Additional file 1. Figure S1. The represent FACS figures of DCs expressed high level of CD11C and MHC Class II.

\section{Acknowledgements}

None.

\section{Authors' contributions}

Conceptualization: CLZ; Methodology: WZ,GBF, and QJX; Manuscript Preparation: ZY. All authors read and approved the final manuscript.

\section{Funding}

The study was supported by Natural Science Foundation of Yongchuan district of Chongqing (Ycstc, 2017nc5023).

\section{Availability of data and materials}

Please contact author for data requests.

\section{Ethics approval}

All animals received care in compliance with the Principles of Laboratory Animal Care and National standards.

\section{Consent for publication}

Not applicable.

\section{Competing interests}

The authors declare that they have no competing interests.

\section{Author details}

${ }^{1}$ Department of orthopedics, Yongchuan Hospital, Chongqing Medical University, Chongqing 402160, China. ${ }^{2}$ Department of Neurology, Yongchuan Hospital, Chongqing Medical University, Chongqing 402160, China.

Received: 19 June 2019 Accepted: 27 January 2020

Published online: 31 January 2020

\section{References}

1. Mascelli S, Barla A, Raso A, Mosci S, Nozza P, et al. Molecular fingerprinting reflects different histotypes and brain region in low grade gliomas. BMC Cancer. 2013:13:387.

2. Jia Z, Wang K, Zhang A, Wang G, Kang C, et al. miR-19a and miR-19b overexpression in gliomas. Pathol Oncol Res. 2013;19:847-53.

3. Patibandla MR, Kumar A, Bhattacharjee S, Sahu BP, Uppin M, et al. Dual gliomas with syringomyelia in a child: case report and literature review. Pediatr Neurosurg. 2012;48:168-73. 
4. Gieryng A, Pszczolkowska D, Bocian K, Dabrowski M, Rajan WD, et al. Immune microenvironment of experimental rat C6 gliomas resembles human glioblastomas. Sci Rep. 2017;7:17556.

5. Yin A, Etcheverry A, He Y, Aubry M, Barnholtz-Sloan J, et al. Integrative analysis of novel hypomethylation and gene expression signatures in glioblastomas. Oncotarget. 2017;8:89607-19.

6. Korshunov A, Chavez L, Sharma T, Ryzhova M, Schrimpf D, et al. Epithelioid glioblastomas stratify into established diagnostic subsets upon integrated molecular analysis. Brain Pathol. 2018;28:656-62.

7. Ho KH, Chen PH, Hsi E, Shih CM, Chang WC, et al. Identification of IGF-1enhanced cytokine expressions targeted by miR-181d in glioblastomas via an integrative miRNA/mRNA regulatory network analysis. Sci Rep. 2017;7:732.

8. Boujelben A, Watson M, McDougall S, Yen YF, Gerstner ER, et al. Multimodality imaging and mathematical modelling of drug delivery to glioblastomas. Interface Focus. 2016;6:20160039.

9. Guadagno E, Borrelli G, Califano M, Cali G, Solari D, et al. Immunohistochemical expression of stem cell markers CD44 and nestin in glioblastomas: evaluation of their prognostic significance. Pathol Res Pract. 2016;212:825-32.

10. Fischer U, Struss AK, Hemmer D, Pallasch CP, Steudel WI, et al. Gliomaexpressed antigen 2 (GLEA2): a novel protein that can elicit immune responses in glioblastoma patients and some controls. Clin Exp Immunol. 2001;126:206-13.

11. Behrends U, Schneider I, Rossler S, Frauenknecht H, Golbeck A, et al. Novel tumor antigens identified by autologous antibody screening of childhood medulloblastoma cDNA libraries. Int J Cancer. 2003;106:244-51.

12. Mock A, Warta R, Geisenberger C, Bischoff $R$, Schulte A, et al. Printed peptide arrays identify prognostic TNC serumantibodies in glioblastoma patients. Oncotarget. 2015;6:13579-90.

13. Hu Z, Ma Y, Shang Z, Hu S, Liang K, et al. Improving immunotherapy for colorectal cancer using dendritic cells combined with anti-programmed death-ligand in vitro. Oncol Lett. 2018;15:5345-51.

14. Seya T, Takeda Y, Takashima K, Yoshida S, Azuma M, et al. Adjuvant immunotherapy for cancer: both dendritic cell-priming and check-point inhibitor blockade are required for immunotherapy. Proc Jpn Acad Ser B Phys Biol Sci. 2018;94:153-60.

15. Homma S, Hayashi K, Yoshida K, Sagawa Y, Kamata Y, et al. Nafamostat mesilate, a serine protease inhibitor, suppresses interferon-gamma-induced up-regulation of programmed cell death ligand 1 in human cancer cells. Int Immunopharmacol. 2018;54:39-45.

16. Mu C, Zhang $X$, Wang $L, X u A$, Ahmed KA, et al. Enhanced suppression of polyclonal CD8(+)25(+) regulatory $T$ cells via exosomal arming of antigenspecific peptide/MHC complexes. J Leukoc Biol. 2017;101:1221-31.

17. Laoui D, Keirsse J, Morias Y, Van Overmeire E, Geeraerts X, et al. The tumour microenvironment harbours ontogenically distinct dendritic cell populations with opposing effects on tumour immunity. Nat Commun. 2016;7:13720.

18. Azuma M, Takeda $Y$, Nakajima H, Sugiyama H, Ebihara T, et al. Biphasic function of TLR3 adjuvant on tumor and spleen dendritic cells promotes tumor $T$ cell infiltration and regression in a vaccine therapy. Oncoimmunology. 2016;5:e1188244

19. Sun JC, Pan K, Chen MS, Wang QJ, Wang H, et al. Dendritic cells-mediated CTLs targeting hepatocellular carcinoma stem cells. Cancer Biol Ther. 2010; 10:368-75.

20. Xu Q, Liu G, Yuan X, Xu M, Wang H, et al. Antigen-specific T-cell response from dendritic cell vaccination using cancer stem-like cell-associated antigens. Stem Cells. 2009;27:1734-40.

21. Xie LH, Sin FW, Cheng SC, Cheung YK, Chan KT, et al. Activation of cytotoxic T lymphocytes against CML28-bearing tumors by dendritic cells transduced with a recombinant adeno-associated virus encoding the CML28 gene. Cancer Immunol Immunother. 2008;57:1029-38.

22. Mahato D, De Biase G, Ruiz-Garcia HJ, Grover S, Rosenfeld S, et al. Impact of facility type and volume on post-surgical outcomes following diagnosis of WHO grade II glioma. J Clin Neurosci. 2018;58:34-41.

23. Liu B, Zhao S, Qi C, Zhao X, Hao F, et al. Inhibition of metabotropic glutamate receptor 5 facilitates hypoxia-induced glioma cell death. Brain Res. 2019;1704:241-8.

24. Alhajala HS, Nguyen HS, Shabani S, Best B, Kaushal M, et al. Irradiation of pediatric glioblastoma cells promotes radioresistance and enhances glioma malignancy via genome-wide transcriptome changes. Oncotarget. 2018;9:34122-31.

25. Marra JS, Mendes GP, Yoshinari GH Jr, da Silva GF, Mazin SC, et al. Survival after radiation therapy for high-grade glioma. Rep Pract Oncol Radiother. 2019;24:35-40.
26. Liu T, Xu H, Huang M, Ma W, Saxena D, et al. Circulating Glioma cells exhibit stem cell-like properties. Cancer Res. 2018;78:6632-42.

27. Shi M, Anantha M, Wehbe M, Bally MB, Fortin D, et al. Liposomal formulations of carboplatin injected by convection-enhanced delivery increases the median survival time of F98 glioma bearing rats. J Nanobiotechnology. 2018;16:77.

28. Liu Z, Poiret T, Persson O, Meng Q, Rane L, et al. NY-ESO-1- and survivinspecific T-cell responses in the peripheral blood from patients with glioma. Cancer Immunol Immunother. 2018;67:237-46.

29. Cockle JV, Rajani K, Zaidi S, Kottke T, Thompson J, et al. Combination viroimmunotherapy with checkpoint inhibition to treat glioma, based on location-specific tumor profiling. Neuro-Oncology. 2016;18:518-27.

30. Sakai K, Shimodaira S, Maejima S, Udagawa N, Sano K, et al. Dendritic cellbased immunotherapy targeting Wilms' tumor 1 in patients with recurrent malignant glioma. J Neurosurg. 2015;123:989-97.

31. Samaha H, El Naggar S, Ahmed N. Armed hunter killers: discerning the role of adoptive T-cell transfer for glioblastoma. Immunotherapy. 2015;7:481-5.

32. Flores C, Pham C, Snyder D, Yang S, Sanchez-Perez L, et al. Novel role of hematopoietic stem cells in immunologic rejection of malignant gliomas. Oncoimmunology. 2015;4:e994374.

33. Pallasch CP, Struss AK, Munnia A, Konig J, Steudel WI, et al. Autoantibodies against GLEA2 and PHF3 in glioblastoma: tumor-associated autoantibodies correlated with prolonged survival. Int J Cancer. 2005;117:456-9.

\section{Publisher's Note}

Springer Nature remains neutral with regard to jurisdictional claims in published maps and institutional affiliations.
Ready to submit your research? Choose BMC and benefit from:

- fast, convenient online submission

- thorough peer review by experienced researchers in your field

- rapid publication on acceptance

- support for research data, including large and complex data types

- gold Open Access which fosters wider collaboration and increased citations

- maximum visibility for your research: over $100 \mathrm{M}$ website views per year

At BMC, research is always in progress.

Learn more biomedcentral.com/submissions 